and the stomach was again washed out. On the table, when going under chloroform she had her last seizure, becoming livid in the face and rigid in the limbs.

On opening the abdomen to the left of the middle line above and below the umbilicus we found the dilated stomach intensely congested and contracting freely against the pylorus, which was very hard but free from adhesions and almost touching the cardia. Picking up the jejunal loop, also turgid, a posterior anastomosis was performed by simple suture, the stomach being fixed in the rent in the mesocolon by three fixing sutures and the abdomen was rapidly shut by one layer of fishing-gut sutures. The pulse fell to 80 on the evening after operation and the patient passed through an uneventful convalescence, with the exception of a slight parotitis on the fourth day which quickly disappeared. The urine lost the trace of albumin in about ten days but a certain stiffness in the fingers of both hands, but more so in the right, persisted for the three weeks during which she remained in the clinique. She is now on ordinary diet and in the best of health, having gained weight greatly.

Although previously to the operation the patient had apparently lucid intervals between the tetanic seizures she probably never returned to real consciousness, as she has no recollection of being brought to the clinique or of being removed to the operating theatre.

Huelva, Spain.

\section{DIPHTHERIA IN A PATIENT 79 YEARS OF AGE, WITH SUBSEQUENT FREEDOM FROM OLD GOUTY SYMPTOMS.}

By JOSEPH BIRT, M.R.C.S. ENG., L.R.C.P. EDIN.

A PATIENT, $7 \ni$ years of age, who had included amongst her country-house changes a sojourn at one of the English spas for the relief of general goutiness and neuritis (troubles of about eight years' standing), sent for me on the afternoon of Sept. 24th to examine her throat. She stated that although she had been able as usual to take part in the singing at church in the morning she felt, on returning home, distinct pain on the left side of her throat, describing it "as if something had broken in it." The history of the case so far was that on Sept. 20th she visited relatives in one of the home counties at whose house "throats" shortly after developed, both amongst visitors and servants. One of the throats was diagnosed as diphtheria on the 23rd and my patient left at once upon advice, although she did not consult the medical man in attendance regarding a slight discomfort she herself was feeling. When I first saw the patient the left tonsil was inflamed. The temperature was normal, the pulse was 84, and the general condition was good. I ordered a mixture of tincture of perchloride of iron and chlorate of potassium and a throat spray of carbolic acid lotion. On the 25th she was not so well, having had an indifferent night and the throat having secreted a good deal of thick slime. The temperature was $101^{\circ} \mathrm{F}$, the pulse was 96 , the glands under the left jaw were very tender and much swollen, and the appetite was mooerately good but swal'owing was painful. I rubbed over the tonsil a cotton-wool swab and sent it to be examined bacteriologicalls, procuring at once some diphtheria antitoxin. Of this I injected 2000 units under the skin of the abdomen. The left tonsil was now thickly covered with membrane and the glands were exquisitely tender, swallowing being attended with much pain. Albumin was present in the urine and the patient was very ill. I ordered fluid nourishment to be given in small quantities and two teaspoonfuls of whisky, diluted, every two or three hours. On the 26th the temperature was subnormal and the pulse was 84 ; the bowels had acted and the patient was feeling better, there having been very little secretion of slime. The bacteriological report was that the Klebs-Löffler bacillus bad been cultivated. The patient now informed me that two hours after the antitoxin injection all the old gouty stiffness and neuritis had disappeared and that for the first time for several years she was able to turn in bed with absolute freedom from pain and stiffness. On this evening the membrane on the left tonsil was almost detached and the glands on the same side were subsiding, but the right tonsil was now becoming covered with membrane and the glands on the corresponding side enlarged, and the throat was again secreting much slime. I therefore injected another 2000 units of antitoxin. The next morning the patient was much better, the membrane on the right tonsil being loose and curled up and the left tonsil being quite clean; the slime had diminished, the temperature was $97^{\circ}$, and the pulse was 84. Liquid nourishment had been adequately taken through the night, with only slight discomfort in swallowing. The patient was inclined to be drowsier than one would have wished and was under the impression that this was due to her having been roused several times to take nourishment but I was inclined to regard it as pathognomonic of the diphtheria poison and stimulants were increased. In the evening I was sent for on account of the development of a very troublesome rash in the neighbourhood of the second injection which was as large as the palm of one's hand and was attended by great irritation. A boric fomentation was applied and in the morning carbolic ointment was used with good result. The next morning progress was still well maintaired, some membrane having been coughed up, and the throat and glands ceasing to bear naked-eye evidence of diphtheria. From this time onwards the patient made steady progress, the temperature rising gradually from subnormal to normal by Oct. 2 nd.

The origin of this outbreak seems to have been from a garden boy who dined in the servants' hall and who for three weeks had had a slight sore-throat and nasal discharge. The village in which the patient was staying was partially supplied by the house in question with milk and there were several similar cases, one being fatal. The point of interest is the fact that two hours after the first injection of antitoxin the neuritis and general goutiness had entirely disappeared and one is led to suppose that this must have been due to the diphtheria or the antitoxin. Four years ago a patient who had had many attacks of acute gout developed pneumonia, since which time until the beginning of this year be had no gout whatever. In this particular instance the pneumonia may have had some neutralising effect on the gouty diathesis.

Belgrave-road, S.W

\section{olinical 筑otes:}

\section{MEDICAL, SURGICAL, OBSTETRICAL, AND THERAPEUTICAL.}

\section{A CASE OF SIMPLE SEPARATION OF THE LOWER EPIPHYSIS OF THE FIBULA WITH INWARD} DISPLACEMENT OF THE FOOT.

By A. F. Missiter, M.R.C.S. ENG., L.R.C.P. LOND.

Mr. J. Poland, in his exhaustive work on "Traumatic Separation of the Epiphyses," makes the following remark about the lower fibular epiphysis: "The author is unable to refer to a single instance of simple separation with or without displacement which has been correctly diagnosed and described during life." The following case, therefore, is worth recording.

The patient, a strongly built girl, aged 19 years, was seen half an bour after a fall from a steam roundabout. The foot was markedly inverted; the sharp edge of the upper fragment of the fibula (fractured transversely one inch above the tip of the malleolus) was threatening to cut through the skin tightly stretched over it and already discoloured. The lower fragment (malleolus), separated from the upper by at least two inches, remained attached to the foot by its ligaments. The astragalus, carrying the rest of the foot with it, was evidently rotated on its antero-posterior axis with its inner surface in contact with the articular surface of the tibia. The displaced foot was quite rigid and immoveable with the leg straight, but with the knee strongly flexed was reduced with tolerable ease by manipulation and traction, the malleolus meeting the upper fragment of the fibula without crepitus or deformity. After reduction there was no pain, tenderness, or swelling in the neighbourhood of the inner malleolus which had evidently escaped injury. A millboard and starch case was applied for four weeks, at the end of which time alaptation and union were found. 